\title{
Reprint of: Continuous renal replacement therapy and mild hypothermia for acute left heart failure after cardiovascular surgery*
}

\author{
Yu Du, MM, Haitao Zhang, MM, and Xue Feng, MD
}

See related commentary on page 606 .

Management of severe heart failure with high doses of inotropes and vasopressors and increased ventricular volume will result in a high work load for the failing heart, with progressive decompensation. Recovery of heart function as a result of a period of rest for a failing heart has been well documented. However, few hospitals in China currently have the resources to provide extracorporeal membrane oxygenation or left ventricular assist device services. Management has continued to be a major challenge for cardiovascular surgical teams. We report a new strategy of combined continuous renal replacement therapy (CRRT) and mild hypothermia (MHT) to provide a period of rest for the severely failing heart to achieve recovery of cardiac function adequate for survival.

\section{CASE REPORT}

A 31-year-old man with Marfan syndrome underwent an emergency Bentall procedure for acute aortic dissection with aortic insufficiency. The preoperative left ventricular ejective fraction was $32 \%$, and he was in New York Heart Association class IV. The cardiopulmonary bypass time was 75 minutes, and the crossclamp time was 45 minutes. Postoperative acute left heart failure was diagnosed from the clinical manifestations, hemodynamic data, and ultrasound findings. It was initially managed with high doses of inotropes and vasopressors (eg, dopamine,

DOI of original article: http://dx.doi.org/10.1016/j.jtcvs.2014.03.043

* This article is a reprint of a previously published article. For citation purposes, please use the original publication details; J Thorac Cardiovasc Surg. 2014;148:e137-9.

From the Department of Surgical Intensive Care Unit, State Key Laboratory of Cardiovascular Disease, Fuwai Hospital, National Center for Cardiovascular Diseases, Chinese Academy of Medical Sciences and Peking Union Medical College, Beijing, China.

Disclosures: Authors have nothing to disclose with regard to commercial support.

Presented at the FACTS-Care Annual Meeting, Cardiovascular-Thoracic Critical Care 2013, Washington, DC, October 10-12, 2013.

Received for publication Sept 26, 2013; revisions received March 12, 2014; accepted for publication March 21, 2014; available ahead of print April 17, 2014.

Address for reprints: Haitao Zhang, MM, Department of Surgical Intensive Care Unit,

Fuwai Hospital, 167 North LiShi Ave, XiCheng District, Beijing 100037, China

(E-mail: boy398672@aliyun.com).

J Thorac Cardiovasc Surg 2015;149:604-6

$0022-5223 / \$ 36.00$

Copyright (C) 2015 by The American Association for Thoracic Surgery

http://dx.doi.org/10.1016/j.jtcvs.2014.12.001 epinephrine, norepinephrine) to maintain a mean artery pressure $>70 \mathrm{~mm} \mathrm{Hg}$. The cardiac index (CI) was $<2.2 \mathrm{~L} / \mathrm{min} / \mathrm{m}^{2}$. The pulmonary artery wedge pressure (PAWP) was $>20 \mathrm{~mm} \mathrm{Hg}$, and the left ventricular ejection fraction was $<30 \%$. The urine output was $<0.5 \mathrm{~mL} / \mathrm{kg}$ for 6 hours, and the arterial lactate was $>3.0 \mathrm{mmol} / \mathrm{L}$. A pulmonary artery catheter was used to continuously monitor the cardiac output and core temperature. At 21 hours after surgery, CRRT was started with a Prisma automatic continuous renal replacement system (Gambro Dasco SpA, Medolla, Italy). During CRRT, the extracorporeal circulation lines were submerged in ice water to maintain the core body temperature at $34^{\circ} \mathrm{C}$. His core body temperature was $38.8^{\circ} \mathrm{C}$ before CRRT/MHT and decreased to $34.2^{\circ} \mathrm{C}$ after 3 hours of treatment. The fluid intake and output were adjusted such that the fluid output was greater than his intake, and the PAWP was 10 to $12 \mathrm{~mm} \mathrm{Hg}$. The PAWP decreased from 23 to $13 \mathrm{~mm} \mathrm{Hg}$ after 10 hours of treatment and was maintained at 10 to $12 \mathrm{~mm} \mathrm{Hg}$ during the entire period of CRRT/MHT. The dosages of inotropes and vasopressors were gradually reduced to maintain the mean artery pressure at 60 to $70 \mathrm{~mm} \mathrm{Hg}$ and CI at $>1.0 \mathrm{~L} / \mathrm{min} / \mathrm{m}^{2}$. An intravenous heparin infusion was used to maintain the activated whole blood clotting time at 120 to 140 seconds. Replacement therapy included maintaining the plasma albumin at $>35 \mathrm{~g} / \mathrm{L}$ and platelet count at $>5.5 \times 10^{9} / \mathrm{L}$. During CRRT/MHT, the doses of inotropes and vasopressors were substantially decreased (Figure 1). By the fifth day of CRRT/MHT, his cardiac function had gradually recovered. When the CI had increased to 1.8 to $2.2 \mathrm{~L} / \mathrm{min} / \mathrm{m}^{2}$, with the PAWP stable at 10 to $12 \mathrm{~mm} \mathrm{Hg}$ and the echocardiogram showed improved contractility of the myocardium with a left ventricular ejection fraction $>45 \%$, the core body temperature was gradually increased to $37.3^{\circ} \mathrm{C}$. Also, the dose of inotropes and the volume load were adjusted to maintain the mean artery pressure at 80 to $85 \mathrm{~mm} \mathrm{Hg}$. CRRT was gradually discontinued. The total CRRT period was 136 hours. With the institution of CRRT/MHT, the CI had decreased from 2.0 to 1.7 $\mathrm{L} / \mathrm{min} / \mathrm{m}^{2}$. After CRRT/MHT was discontinued, the CI had increased to $3.4 \mathrm{~L} / \mathrm{min} / \mathrm{m}^{2}$. During the CRRT/MHT period, he had had nearly no urine output, and serum creatinine was controlled at 98 to $130 \mathrm{mmol} / \mathrm{L}$ using CRRT. The urine output had recovered to normal by 48 hours after the CRRT had been discontinued, and his renal function had recovered to normal without additional 

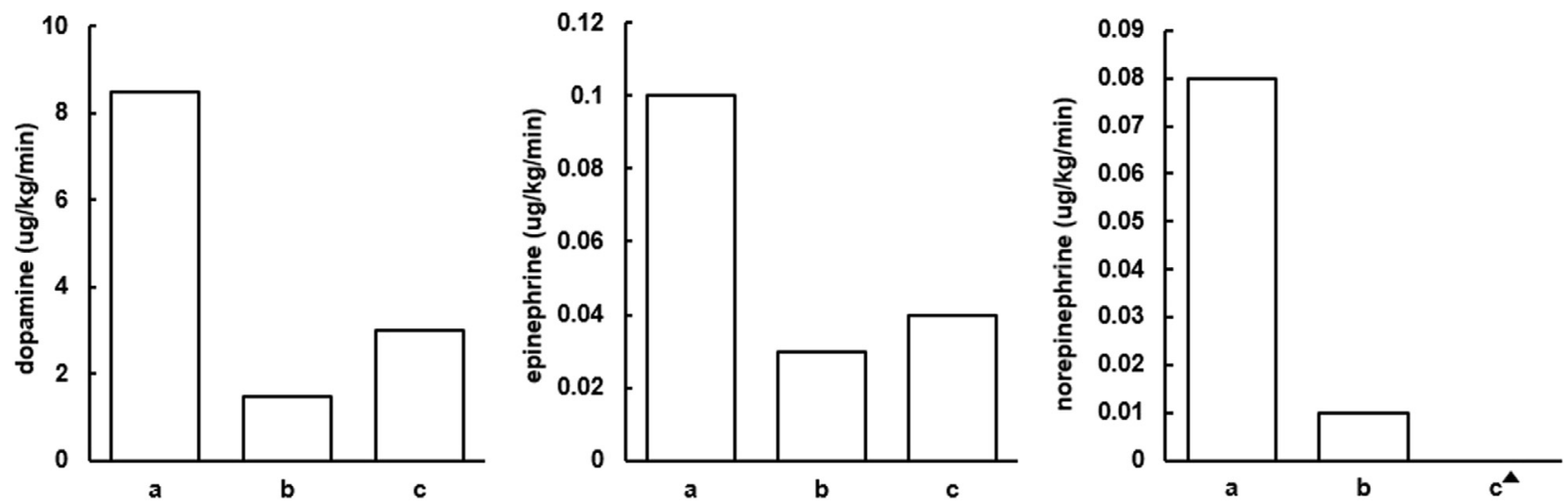

FIGURE 1. Dosages of dopamine, epinephrine, and norepinephrine before continuous renal replacement therapy (column a), during CRRT (column b), and after CRRT discontinuation (column c). Black triangle indicates the amount of norepinephrine was 0.

renal replacement therapy. The patient survived in the intensive care unit and hospital.

\section{DISCUSSION}

The primary goal of the CRRT/MHT strategy was to reduce the work of the heart to facilitate recovery of myocardial function. Catecholamine use was substantially decreased and could well have importantly contributed to the reduction in cardiac oxygen consumption and survival of the patient. Myocardial recovery and the reduction of catecholamine drugs could have been facilitated by the positive inotropic effect of mild hypothermia, ${ }^{1}$ the increased systematic vascular resistance contributed by the mild hypothermia, ${ }^{2}$ and the correction of acidosis by CRRT.

As the temperature decreases by $1^{\circ} \mathrm{C}$, the overall metabolic rate will decrease by about $8 \%$. When the temperature has decreased to $32^{\circ} \mathrm{C}$, the overall metabolic rate will decrease by about $50 \%$ to $60 \%$, and, accordingly, oxygen consumption and carbon dioxide production will be reduced. ${ }^{3}$ With the decreased metabolic demand, mild hypothermia will result in an important decrease in the work of the heart. A new metabolic balance will be reached under mild hypothermia, and organ perfusion can better supply the metabolic needs in the presence of acute heart failure and gain time for recovery of cardiac function adequate for survival.

CRRT reduces the cardiac preload promptly by ultrafiltration. ${ }^{4}$ When this has been accompanied by a reduction in the use of inotropes and vasopressors, the work of the heart and overall oxygen consumption will decline, achieving "unloading" of the heart. CRRT controls the body temperature rapidly and accurately and has also been effective in avoiding the chills and pressure sores seen with surface cooling.

In our clinical practice, an additional 11 patients have experienced acute left heart failure after cardiac surgery

TABLE 1. Data from another 11 patients with acute left heart failure after cardiac surgery who underwent CRRT/MHT strategy

\begin{tabular}{|c|c|c|c|c|c|c|c|c|c|}
\hline Pt. no. & Age (y) & Gender & Primary illness & Procedure & $\begin{array}{c}\text { Preoperative } \\
\text { EF }(\%) / \text { NYHA } \\
\text { class }\end{array}$ & $\begin{array}{c}\text { Interval to } \\
\text { initiation of } \\
\text { CRRT/MHT } \\
\text { postoperatively (h) }\end{array}$ & $\begin{array}{c}\text { Total } \\
\text { CRRT/MHT } \\
\text { duration (h) }\end{array}$ & $\begin{array}{l}\text { Survived } \\
\text { in ICU* }\end{array}$ & $\begin{array}{c}\text { Survived } \\
\text { in hospital }\end{array}$ \\
\hline 1 & 39 & $\mathrm{~F}$ & $\mathrm{AD}+\mathrm{AI}+\mathrm{MR}$ & Bentall + TS + MVR & 47/III & 8 & 164 & Yes & Yes \\
\hline 2 & 27 & M & $\mathrm{AD}+\mathrm{AI}+\mathrm{MR}$ & Bentall + MVR & $71 / \mathrm{II}$ & 15 & 155 & Yes & Yes \\
\hline 3 & 37 & $\mathrm{~F}$ & $\mathrm{AD}$ & ATS & $67 / \mathrm{II}$ & 22 & 105 & Yes & No \\
\hline 4 & 65 & $\mathrm{~F}$ & CHD & CABG & $65 / \mathrm{II}$ & 17 & 170 & Yes & Yes \\
\hline 5 & 54 & $\mathrm{~F}$ & MR & MVR & $59 / \mathrm{III}$ & 25 & 135 & Yes & Yes \\
\hline 6 & 41 & $\mathrm{~F}$ & $\mathrm{AD}$ & ATS & $70 / \mathrm{II}$ & 32 & 116 & Yes & Yes \\
\hline 7 & 40 & $\mathrm{~F}$ & $\mathrm{AD}$ & ATS & 54/III & 14 & 111 & Yes & Yes \\
\hline 8 & 57 & M & $\mathrm{MS}+\mathrm{MR}$ & $\mathrm{MVR}+\mathrm{TVP}$ & $41 / \mathrm{IV}$ & 16 & 183 & Yes & Yes \\
\hline 9 & 17 & $\mathrm{~F}$ & TOF & TOF correction & $51 / \mathrm{II}$ & 20 & 179 & No & - \\
\hline 10 & 25 & $\mathrm{~F}$ & MS & MVR & $52 / \mathrm{III}$ & 10 & 163 & Yes & Yes \\
\hline 11 & 55 & M & $\mathrm{MS}+\mathrm{MR}+\mathrm{AS}$ & MVR + TVP & 63/III & 22 & 143 & No & - \\
\hline
\end{tabular}

No persistent renal failure occurred that required dialysis. Pt. no., Patient number; $E F$, ejection fraction; NYHA, New York Heart Association; $C R R T$, continuous renal replacemen therapy; $M H T$, mild hypothermia; $I C U$, intensive care unit; $F$, female; $A D$, aortic dissection; $A I$, aortic insufficiency; $M R$, mitral regurgitation; $T S$, total arch replacement combined with stented elephant trunk implantation; $M V R$, mitral valve replacement; $M$, male; $A T S$, ascending aorta and total arch replacement combined with stented elephant trunk implantation; $C H D$, coronary heart disease; $C A B G$, coronary artery bypass grafting; $M S$, mitral stenosis; $T V P$, tricuspid valveplasty; $T O F$, tetralogy of Fallot; $A S$, aortic stenosis. *Two patients died in the ICU of refractory heart failure. †One patient died of rupture of a residual aortic dissection 20 days after cardiac and renal function had recovered to normal. 
and were treated with the CRRT/MHT strategy with good outcomes (Table 1). Similar reports of hypothermia combined with intra-aortic balloon pump support after heart surgery have also been published, with good outcomes. 5,6 Randomized clinical studies are needed to evaluate the efficiency and safety of the CRRT/MHT strategy in acute left heart failure after cardiovascular surgery.

\section{References}

1. Weisser J, Martin J, Bisping E, Maier LS, Beyersdorf F, Hasenfuss G, et al. Influence of mild hypothermia on myocardial contractility and circulatory function. Basic Res Cardiol. 2001;96:198-205.
2. Zobel C, Adler C, Kranz A, Seck C, Pfister R, Hellmich M, et al. Mild therapeutic hypothermia in cardiogenic shock syndrome. Crit Care Med. 2012; 40:1715-23.

3. Polderman KH. Mechanisms of action, physiological effects, and complications of hypothermia. Crit Care Med. 2012;37:186-202.

4. Shiomi H, Matsubara K, Ariyoshi M, Iwamura Y, Fukui K, Sakamoto T, et al. Efficacy and safety of continuous hemodiafiltration for acute decompensated heart failure. Int Heart J. 2010;51:247-51

5. Moriyama Y, Iguro Y, Shimokawa S, Saigenji H, Toyohira H, Taira A. Successful application of hypothermia combined with intra-aortic balloon pump support to low-cardiac-output state after open heart surgery. Angiology. 1996; 47:595-9.

6. Yahagi N, Kumon K, Watanabe Y, Tanigami H, Haruna M, Hayashi H, et al. Value of mild hypothermia in patients who have severe circulatory insufficiency even after intra-aortic balloon pump. J Clin Anesth. 1998;10:120-5.

\title{
EDITORIAL COMMENTARY
}

\section{Innovative strategy for severe left ventricular failure without use of a left ventricular assist device}

\author{
Nevin M. Katz, MD
}

See related article on pages 604-6.

The report from Du and colleagues ${ }^{1}$ at the Fu Wai Hospital in Beijing, China, describes an innovative approach to manage acute severe left ventricular failure without the use of a left ventricular assist device. Hypothermia is now recognized as a valuable technique to allow cerebral recovery after a period of cardiac arrest. With the approach described in this report, the concept is extended to allow myocardial recovery in the postcardiotomy patient with severe acute cardiac failure.

With this strategy, moderate hypothermia permits the reduction of cardiac preload, afterload, and inotrope and vasopressor support, thereby reducing cardiac workload and facilitating myocardial recovery. The management with hypothermia includes renal replacement therapy and full ventilator support to reduce overall metabolic requirements. The goal is to facilitate cardiac recovery without the development of multi-organ system failure.

Although the experience reported is limited to 12 patients, and it is not a prospective, randomized trial, the favorable survival results in these patients with severe acute heart failure are encouraging. In this era of limited hospital and financial resources, this innovative approach may well see application in a variety of situations, especially in hospitals without access to advanced cardiac support technology.

\section{Reference}

1. Du Y, Haitao Zhang H, Feng X. Reprint of: Continuous renal replacement therapy and mild hypothermia for acute left heart failure after cardiovascular surgery. $J$ Thorac Cardiovasc Surg. 2015;149:604-6.
From Division of Cardiac Surgery, Johns Hopkins University, Baltimore, Md; and the Foundation for the Advancement of Cardiothoracic Surgical Care, McLean, Va. Disclosures: Author has nothing to disclose with regard to commercial support.

Received for publication Oct 28, 2014; accepted for publication Oct 29, 2014

Address for reprints: Nevin M. Katz, MD, Johns Hopkins Hospital, 1800 Orleans St,

Suite 7107, Baltimore, MD 21287-4618 (E-mail: nevinkatz@aol.com).

J Thorac Cardiovasc Surg 2015;149:606

$0022-5223 / \$ 36.00$

Copyright (c) 2015 by The American Association for Thoracic Surgery

http://dx.doi.org/10.1016/j.jtcvs.2014.10.121 